\title{
Rebooting ethics education in the digital age
}

\section{Simon Rogerson}

1951 was the year that J. Lyons \& Co. used a computer (LEO) to manage stock for its renowned chain of over 200 high-street cafes and tea shops. It was the first time across the world that computers were used commercially for business data processing (Ferry, 2003) and marked a sea change. 1995 was the year that Apple launched its first WWW server, Quick Time On-line. It was the year Microsoft released Internet Explorer and sold 7 million copies of Windows 95 in just 2 months. This was a second global sea change; the move away from computers and data processing to the digital age via the information superhighway. It was a move away from highly educated, usually, men in lab coats undertaking elitist science and technology, shifting to a world where almost everybody uses accessible digital technology which could have been developed by almost anyone including young children and elderly adults.

In the digital age it is people who change things. It is people who make digital technology. It is people who use and abuse digital technology. The tension between use and abuse is where the ethical hotspots lie. Digital technology can add value to life, but it can also take value away from life. Some ethical hotspots may be obvious whilst others may not. All must be addressed so that the digital age is good for everyone as well as for the world at large. This can only be achieved through effective digital ethics education and awareness programmes. Such programmes should promote social responsibility which should aim to (Rogerson, 2004):

- Develop a socially responsible culture within work, home and society which nurtures moral individual action

- Consider and support the wellbeing of all stakeholders

- Account for global common values and local cultural differences

- Recognise social responsibility is beyond legal compliance and effective fiscal management

- Ensure all processes are considered from a social responsibility perspective

- Be proactive rather than reactive when addressing the development and use of digital technology

Digital ethics education and awareness must develop the individual's confidence and skills, through lifelong learning, and so provide the tools to enable everyone to act responsibly and ethically. Discussion, dialogue, storytelling, case study analysis, mentoring, and counselling are examples of techniques that can be used to nurture practical wisdom and insight which will lead to virtuous citizens of the digital age. 
Digital ethics education needs to be rebooted because the current effort seems to be too narrowly focused and so is probably ineffective. For example, Grosz et al (2019) discuss a recent initiative by Harvard to embed ethics in the computer science degree curriculum. The initiative has been heralded by many, but it is problematic in that it simply reinvents the wheel of computer ethics education which has a long and comprehensive history stretching back to the 1980s. It offers little new insight and does not link to a 40-year history and experience. It misaligns with the demographic profile of the computing community in the digital age and fails to acknowledge that digital ethics education in the post millennial era is best started from early childhood. Similarly, this misalignment seems to be the case with the proposals by Blundell (2020) in the December 2020 edition of ITNOW, the membership magazine of BCS, The Chartered Institute for IT, which featured lifelong learning.

The IDC 2018 survey (www.idc.com/getdoc.jsp?containerId=US44363318. accessed July 2019) found that there were 18 million professional software developers and 4.3 million hobbyists. According to the published membership figures of the leading computing professional bodies, only $3 \%$ of the total 22.3 million belong to a professional body. This suggests that professional bodies, in their current role, have little influence on 97 percent of global software developers whose moral code and attitude to social responsibility comes from elsewhere.

It is not that ongoing digital ethics training as part of professional development programmes is wrong; it is that this should not be the only or dominant element in the digital ethics education landscape. Those entering the computing profession are faced with a plethora of application areas using a vast digital technology armoury. For new entrants, the responsibilities and obligations to society are onerous. Yet it is uncertain how well they are prepared for such challenges and whether they have been educated to understand that they are the custodians of the most powerful and flexible technology humankind has invented. Too many computing professionals hide in technological clouds seemingly indifferent to the ethically charged nature of digital technology. It is unclear whether this is through lack of awareness or a belief such issues are outside their scope of responsibility. The VW emissions scandal is a prime example (Rogerson, 2018).

Digital ethics education for everyone should start at an early age and in that way the foundations are laid for responsible adulthood in the digital age. This is a challenging proposition for as Churchland (1996) explains, the development of moral character in children takes time. The formality of school, and the informality of home and social settings are equally important, particularly in the early stages 
of this journey to moral maturity. It is a journey which starts the moment a child is born, continues through childhood into adolescence and finally into adulthood. Novel cross-discipline educational experiences should be developed which capture the interest and imagination of learners thereby firmly establishing digital ethics as a pillar of their conduct and their participation in the digital age. Some possible avenues to explore are (Rogerson, 2020a):

- Interactive digital ethics exhibitions in science and technology museums;

- Investigating social impacts across the history of computing;

- Using thought experiments to explore dual use dilemmas in digital technology; and

- Using poetry to understand the breadth and depth of digital ethics.

Such avenues also offer greater awareness to the public at large and align with Burton et al (2018), who use science fiction to teach digital ethics.

Rogerson (2020a) discusses the four possible avenues in some detail, however, the last of these avenues, poetry, has been explored in more detail (Rogerson, 2020b). Poetry challenges us to think beyond the obvious and reflect on what has been, what is and what might be. Poetry can reboot the way in which social impact education is delivered to technologists. Rule et al (2004) explain that incorporating poetry in science and technology teaching expands the curriculum beyond subject knowledge and process skills. Poems can provide meaningful context. Such context is imperative in digital ethics education and awareness at all levels for all people, enabling understanding of the social impacts of digital technology. In partnership, computer science and liberal arts educators could offer an exciting new perspective through poetry as an instrument of presentation and discussion as well as in creative exercises for students of all ages.

It would be appropriate to underpin the digital ethics education reboot with a global beacon. This could be a global digital technology charter which aligned to, for example, The Universal Declaration of Human Rights. Through adapting the work of Franklin (1999) and Barratt (2007), a simple charter has been devised (Rogerson, 2015) which encourages everyone to:

- promote social justice and social care

- restore reciprocity for everyone

- benefit the many rather than the few

- put people first rather than digital technology

- limit economic gain to minimise potential social and environmental cost

- favour the reversible over the irreversible

- create a more inclusive society by reducing barriers and creating new opportunities 
We have to accept and adjust to the fact that we are all technologist to a lesser or greater degree. How we educate our future generations must reflect this change to ensure digital technology is societally beneficial. The time has come to reboot ethics education in the digital age.

\section{Reference}

Barratt, J. (2007). Design for an ageing society. Gerontechnology, 6(4), pp.188-189.

Blundell, B.G. (2020). Ethics and Lifelong Learning. Itnow, 62(4), pp.22-23.

Burton, E., Goldsmith, J. \& Mattei, N. (2018). How to teach computer ethics through science fiction. Communications of the ACM, 61(8), 54-64.

Churchland, P.M., (1996). The neural representation of the social world. In: May, L., Friedman, M. \& Clark, A., (Editors). Mind and morals: Essays on cognitive science and ethics. The MIT Press. 91-108.

Ferry, G. (2003). A Computer Called LEO: Lyons Teashops and the World's First Office Computer. London: Fourth Estate. ISBN: 978-1-84115-185-4.

Franklin, U.M. (1999). The real world of technology. House of Anansi Press.

Grosz, B. J., Grant, D. G., Vredenburgh, K., Behrends, J., Hu, L., Simmons, A. \& Waldo, J. (2019). Embedded EthiCS: integrating ethics across CS education. Communications of the ACM. 62(8), 5461.

Rogerson, S. (2004). Aspects of social responsibility in the information society. In Social and Economic Transformation in the Digital Era. 31-46. IGI Global.

Rogerson S. (2015). ICT Codes of Ethics. Keynote Presentation, Ethics Conference 2015, Council of European Professional Informatics Societies (CEPIS), 7 April, The Hague, The Netherlands.

Rogerson, S., (2018). Ethics omission increases gases emission: A look in the rearview mirror at Volkswagen software engineering. Communications of the ACM. 61(3), 30-32.

Rogerson, S., (2020a). Start A Revolution in Your Head!: The Rebirth of ICT Ethics Education. In Societal Challenges in the Smart Society, ETHICOMP Book Series, 153-164, Universidad de La Rioja.

Rogerson, S. (2020b). Poetical potentials: the value of poems in social impact education. ACM Inroads, 11(1), 30-32.

Rule, A.C., Carnicelli, L.A. and Kane, S.S. (2004). Using poetry to teach about minerals in earth science class. Journal of Geoscience Education, 52(1), 10-14. 